\title{
Cost-Saving Opportunities for Taylor's University Daily Energy Consumption
}

\author{
Shun Seng Chan ${ }^{1}$, Chockalingam Aravind Vaithilingam ${ }^{1 *}$, Gowthamraj Rajendran ${ }^{1}$ \\ ${ }^{1}$ High Impact Research Lab, School of Engineering, Taylor's University Lakeside Campus, Subang \\ Jaya, Selangor, Malaysia, 47500.
}

\begin{abstract}
Solar energy is a renewable energy abundant throughout the year in a tropical weather country like Malaysia. This paper investigates the viability of using solar PV systems as a cost-saving measure to supply electricity for Taylor's University (TU) daily energy usage. Experimental values were compared with theoretical values and analyzed in this paper. In this experiment, four photovoltaic (PV) panels connected in parallel were linked to a maximum power point tracking (MPPT) charge controller acting as a voltage regulator. A lead-acid battery was also coupled to the controller that acts as an energy storage to store the harvested solar energy from PV panels and discharge it in electricity. Temperature sensors connected to an Arduino UNO were placed at different locations on the solar panels to monitor for irregularities in the temperature of the panels. The amount of electricity produced was calculated using the data obtained. The results showed that using a larger PV system will generate much more electricity and create a high return on investment (ROI) if the solar panels absorbed sunlight under good weather conditions, thus bringing forward a potential solution to reduce TU's electricity consumption.
\end{abstract}

\section{Introduction}

Present-day energy demand is mostly delivered by fossil fuel. Pehnt stated that fossil fuels would run out in the next 37 years globally [1]. Hence, many studies and research were done on renewable energy sources to reduce the heavy dependency on fossil fuels. Figure 1 shows a comparison of electricity generation from different sources worldwide.

Taylor's University (TU) has been paying an average of RM461098.26 in its monthly electricity bill, whereby an average of $977.5 \mathrm{MWh}$ of electricity is being consumed monthly [3]. TU is situated in Malaysia, where the tropical climate is hot and receives constant sunlight all year long. Thus, solar energy is identified as a clean, sustainable, and renewable energy source that can be harvested to generate electricity on TU. This method will become the secondary source of electricity generation and acts as a cost-saving opportunity for TU daily energy consumption.

Solar energy is used marginally in Malaysia as solar technology is deemed expensive and has low productivity with high capital cost [4]. The National Academy of Engineering (NAE) made one of the 14 grand challenges to be "Make solar energy economical" in an attempt to

\footnotetext{
* Corresponding author: aravindcv@ieee.org
} 
make solar energy much more feasible to the people and help reduce their reliance on fossil fuels as well as reducing environmental impact [5]. This has influenced the project to help tackle the grand challenge of making solar energy economical.

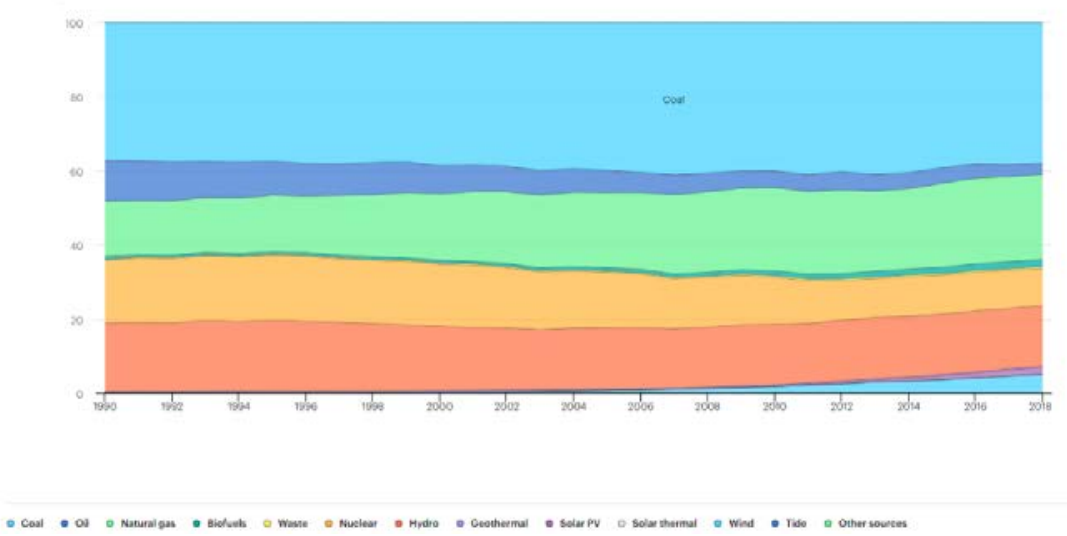

Fig. 1. Global Electricity Generation from Various Sources [2]

There are two ways to harvest solar energy: the first is in heat and the next in light [6]. Concentrating solar power (CSP) power generation systems make use of sunlight focused onto a receiver carrying working fluid to heat the liquid before being transported to a steam turbine connected to a generator that will produce electricity [7,8]. Meanwhile, photovoltaic (PV) cells convert sunlight into electricity, whereby the cells are typically made from a polycrystalline thin film, single-crystalline thin film, or silicon [9]. Connecting the cells in parallel will increase the output current while connecting it in a series to raise the output voltage instead. However, the parallel configuration is advocated as every cell in a solar panel will produce close to the maximum power concurrently regardless of uniform illumination distribution [10]. Continuing from the type of materials of the PV cells, the downside in using these materials is that one could be more expensive than the other but have higher efficiency than the other too [11]. Besides that, this journal article noted that high temperatures acting on the PV cells would reduce its voltage, output power, and efficiency [12].

It is well-known that lead-acid batteries are often chosen as energy storage in terms of a kilowatt-hour $(\mathrm{kWh})$ over other batteries due the lead-acid batteries being cheaper, recyclable, long-lasting, and contain high peak-power [13]. Furthermore, lead-acid batteries have low environmental footprints, rapid response times for simultaneous use in energy management systems, and power quality, easily sited and utilized in implementations of low $\mathrm{kWh}$ to various MWh [14]. These batteries store and supply energy in a PV system by converting electrical energy to chemical energy and vice versa [15]. On the contrary, Anuphappharadorn and her team noted that lead-acid batteries have shorter lifespans and lower energy efficiency [16]. Nevertheless, lead-acid batteries are more economical and ably charge and discharge regularly, making it a useful component in a PV system. This research aims to study the feasibility of using solar PV systems in saving electricity for TU.

\section{Research Methodology}

The experiment was conducted to investigate the viability of using solar PVs to supply electricity to specific loads. The research methodology was as shown in Fig. 2. The selected PV system design was chosen after the electric bill was analyzed, and proper research was 
done to create a proposed solution for TU's daily energy consumption. The solar energy collected and discharged was done through a lead-acid battery while being regulated by a maximum power point tracking (MPPT) charge controller. The experiment was stopped after 1 hour as ample time had been given to create suitable but not ideal conditions for the experiment data to be measured. The experiment started at around 1 p.m. on 13 October 2020 under average solar radiation intensity and partly cloudy weather conditions.

\subsection{Experimental Setup}

The LM35 temperature sensors connected to an Arduino UNO R3 were placed on different solar panels to measure the temperature of the panels, as shown in Fig. 3. The experiment was implemented in the open air under natural sunlight within Taylor's University campus grounds, whereby the experimental setup was as shown in Fig. 4. The solar PVs and 7.2Ah, $12 \mathrm{~V}$ rechargeable lead-acid absorbent glass mat (AGM) batteries were connected parallel to an MPPT charge controller. The batteries act as a storage to store the electricity generated from the solar panels and subsequently supply the stored electricity to the load. The MPPT charge controller was selected for its ability to regulate current to and for the batteries and PV panels to maximize the system's power output. The temperatures were measured to ensure that the whole panel received heat uniformly. The current and voltage produced were not fluctuating; thus, temperature acted as a constant in this experiment.

\subsection{Experimental Procedure}

The experiment was carried out for about an hour. Measurements were taken 30 minutes after the experiment had started under constant solar irradiance conditions. This ensured that the solar panel supplied voltage consistently since the voltage generated by PV decreased with time. Simultaneously, the temperature was measured using temperature sensors in different areas of the solar panels. This was done to check for any irregularities in temperature measured on the PVs that could affect the performance of the solar PVs, leading to reduced efficiency.

\section{Results and Discussion}

The voltages and currents produced by the solar panels stored and discharged from the battery to the load throughout the experiment were measured and recorded in Table 1 below. During the experiment, solar irradiance observed was low, resulting in lower voltages and currents produced. However, the currents and voltages produced were consistent, meaning that the panels were in good working condition and solar irradiance was constant. It must also be noted that the solar panels used have a lifespan of about 20 years, while the lifespan of the battery-operated is around five years. The calculations were separated into two parts since the experiment was done under average sunlight or non-optimal solar irradiance. The cost of the MPPT charge controller was not accounted for as the size of the experiment was small. A light bulb was used to demonstrate that the system functions while the temperature readings showed no irregularities, meaning that the solar panels absorbed a similar amount of heat. Regretfully, the experiment was conducted once before the Malaysian government imposed a lockdown due to the coronavirus pandemic, limiting the time available to build, configure, and carry out the experiment. 


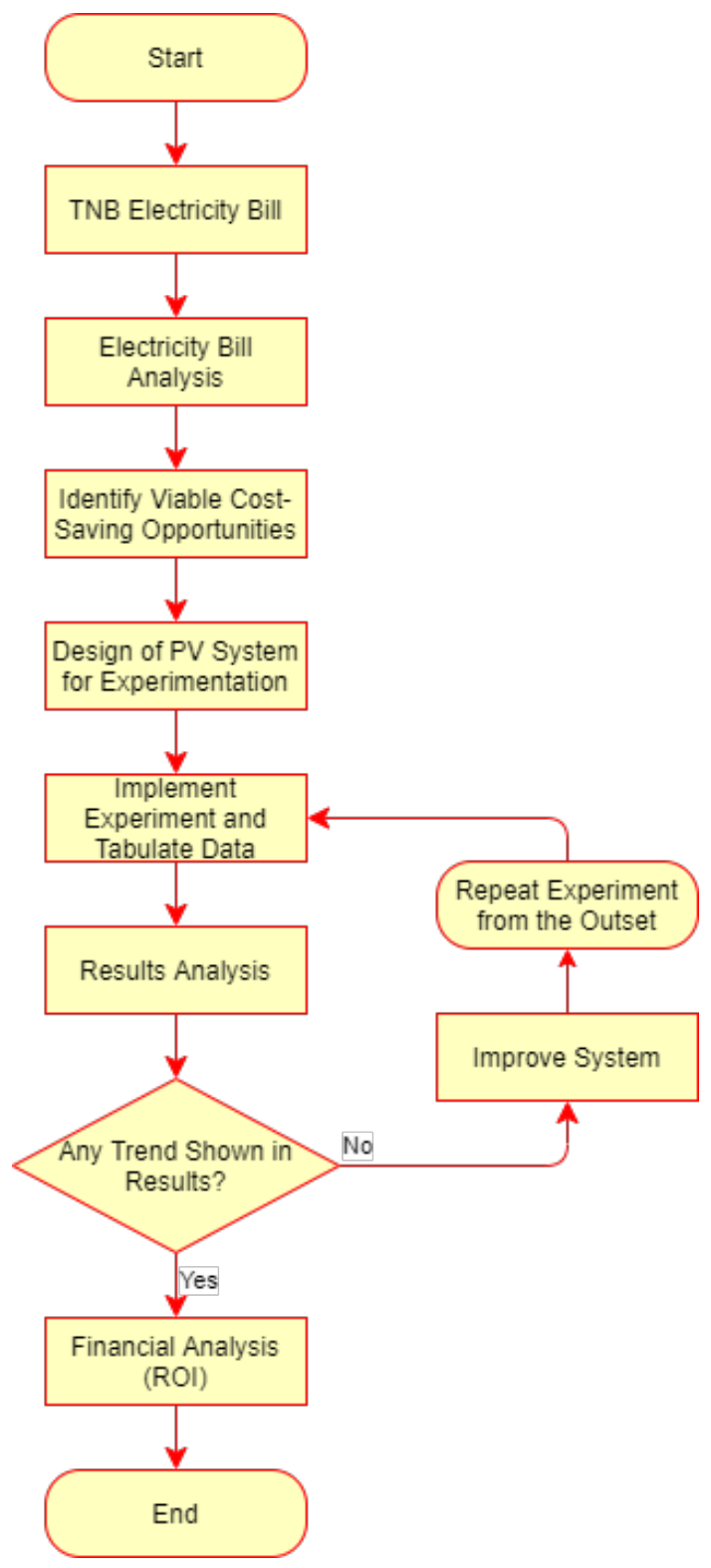

Fig. 2. Flowchart of Research Methodology

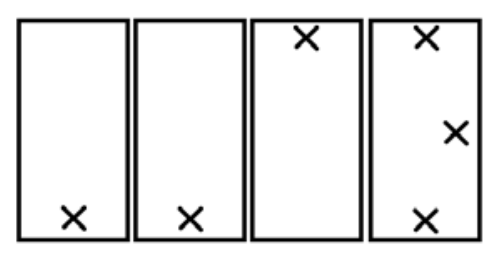

$\mathrm{X}$ - Temperature sensor

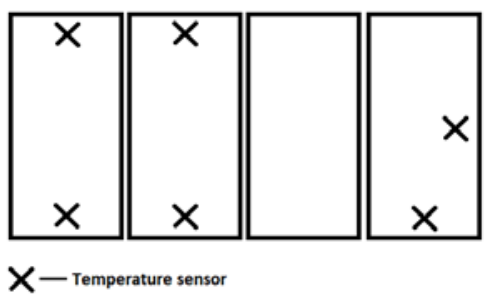

X - Temperature sensor

Fig. 3. Different Layouts of Temperature Sensors on Solar Panels 


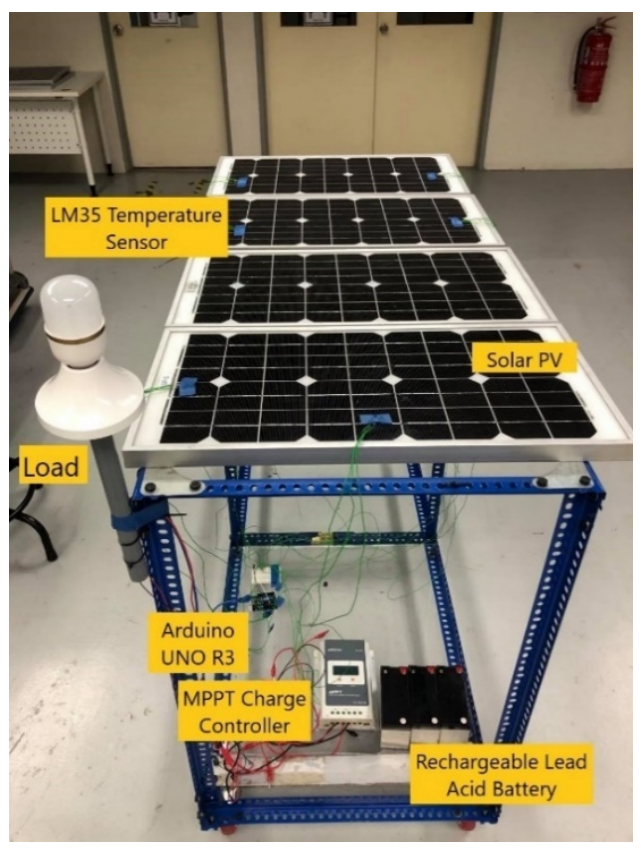

Fig. 4. Experimental Setup

Table 1. Voltage and Current Generated by Solar Panels

\begin{tabular}{|c|c|c|}
\hline Time, $\boldsymbol{m i n}$ & Voltage, $\mathbf{V}$ & Current, A \\
\hline 0 & 19 & 0.6 \\
\hline 5 & 19 & 0.4 \\
\hline 10 & 19 & 0.4 \\
\hline 15 & 19 & 0.4 \\
\hline 20 & 19 & 0.4 \\
\hline 25 & 19 & 0.4 \\
\hline 30 & 19 & 0.4 \\
\hline
\end{tabular}

Table 2. Voltage and Current Generated by Batteries

\begin{tabular}{|c|c|c|}
\hline Time, $\boldsymbol{\text { min }}$ & Voltage, $\mathbf{V}$ & Current, $\mathbf{A}$ \\
\hline 0 & 14.1 & 0.6 \\
\hline 5 & 14.2 & 0.6 \\
\hline 10 & 14.2 & 0.6 \\
\hline 15 & 14.2 & 0.5 \\
\hline 20 & 14.3 & 0.5 \\
\hline 25 & 14.3 & 0.5 \\
\hline 30 & 14.3 & 0.5 \\
\hline
\end{tabular}

\subsection{Experimental Data Calculations}

Electrical output produced by the solar panel: 


$$
\begin{aligned}
\text { Electrical output } & =\text { Voltage } \times \text { Current } \\
& =19 \mathrm{~V} \times 0.4 \mathrm{~A} \\
& =7.6 \mathrm{~W}
\end{aligned}
$$

If 1 kilowatt-hour ( $\mathrm{kWh}$ ) is 1000 watts of electrical energy acting over 1 hour [18], the electrical output generated by solar PV in 1 hour:

$$
\frac{7.6 W \times 1 h}{1000} \times 1 h=0.0076 k W h
$$

Taking solar irradiance availability of 10 hours a day [19] for 365 days in 20 years, the total electrical output generated in that period:

$$
E_{\text {total }}=0.0076 \times 10 \times 365 \times 20=554.8 \mathrm{kWh}
$$

Assume that the rate charged for electricity consumption, RM0.365, remains the same for 20 years, the cost of electricity generated:

$$
\text { Cost of electricity generated }=554.8 \times 0.365=R M 202.50
$$

The cost of the four solar panels used is RM120, while a single lead-acid battery costs RM45. Considering the cost of replacing the battery every five years due to its specific lifespan, the total cost for the set up:

$$
\text { Total cost of set up }=120+(45 \times 4)=R M 300
$$

Return on investment (ROI):

$$
\begin{aligned}
R O I= & \frac{\text { Net Return on Investment }}{\text { Cost of Investment }} \times 100 \% \\
& =\frac{202.50-300}{300} \times 100 \% \\
& =-32.5 \%
\end{aligned}
$$

\subsection{Theoretical Data Calculations}

Assume that the experiment was carried out under direct sunlight and the PV panels generated its maximum power output of $0.03 \mathrm{kWh}$ (maximum value based on PV panel specifications).

Taking solar irradiance availability of 10 hours a day [19] for 365 days in 20 years, the total electrical output generated in that period:

$$
E_{2} \text { total }=0.03 \times 10 \times 365 \times 20=2190 \mathrm{kWh}
$$

Assume that the rate charged for electricity consumption, RM0.365, remains the same for 20 years, the cost of electricity generated:

$$
\text { Cost of electricity generated }=2190 \times 0.365=R M 799.35
$$

Using the same total cost of setting up in experimental data calculations, return on investment (ROI) is: 


$$
\begin{aligned}
\mathrm{ROI}_{2} & =\frac{\text { Net Return on Investment }}{\text { Cost of Investment }} \times 100 \% \\
& =\frac{799.35-300}{300} \times 100 \% \\
& =166.45 \%
\end{aligned}
$$

\section{Conclusion}

In a nutshell, implementing a PV system in TU as a cost-saving solution to help TU lessen its electricity consumption is justified. As TU is paying almost half a million ringgit for its electricity usage, reducing some of that amount will benefit TU and the environment since the carbon footprint is being reduced. This paper displayed the potential of a smallscale PV system that could store energy and supply electricity to TU and how much money could be saved by using this PV system. The electricity produced by the solar panel $(0.0076 \mathrm{kWh})$ was much lower than its maximum electrical output of $0.03 \mathrm{kWh}$. This meant that the cost of electricity produced by the experiment for over 20 years (RM202.50) was significantly lesser than its full potential over the same period (RM799.35). The ROI for the experiment was $-32.5 \%$, while the theoretical ROI was $166.45 \%$. This represented a huge difference in performance that was affected by the surrounding conditions. It was established that under optimal conditions, the PV panels would produce much more electricity and produce a high percentage of ROI. It can be safely said that the electricity cost of TU will be significantly lowered if there were many more solar panels in place. However, the initial costs of implementing a PV system will be high, especially a large one as represented by the negative ROI in the results. The theoretical ROI of $166.45 \%$ indicated that the initial investment was more than doubled. This meant that TU could save up to approximately RM500 for each small-scale PV system in place. Enlarging the PV system would save hundreds of thousands of ringgit within 20 years. Nonetheless, further studies on how much electricity can be produced by a larger PV system had to be done to obtain more precise savings and costs to implement the existing system on TU. The experiment would need to be repeated to make more robust justifications of the results besides testing it on a proposed location in TU so that random errors, mainly caused by surrounding conditions, can be reduced.

\section{References}

1. M. Pehnt, Renew. Energy. 31, 55 (2006)

2. “IEA - International Energy Agency," IEA. Accessed on: Oct. 14, 2020. [Online]. Available: https://www.iea.org

3. “Taylor's University Electricity Bill," Taylor's University, Selangor, Malaysia, 2018.

4. N. Gomesh, I. Daut, M. Irwanto, Y. M. Irwan, M. Fitra, “Energy Procedia, 36, 303(2013)

5. "Make Solar Energy Economical," NAE Grand Challenges for Engineering. Accessed on: Oct. 10, 2020.[Online]. Available: http://www.engineeringchallenges.org/9082.aspx

6. U.S. Department of Energy, “2016 Renewable Energy Data Book,” December 2015, 1132 (2016) 
7. T. M. Pavlović, I. S. Radonjić, D. D. Milosavljević, L. S. Pantić, Renew. Sus. Energy Rev. 16, 891 (2012)

8. M. Peters, T.S. Schmidt, D. Wiederkehr, M. Schneider, Energy Policy. 39, 22 (2011)

9. A. Khaligh, O.C. Onar, CRC Press: Boca Raton, 223-225 (2009)

10. L. Gao, R. A. Dougal, S. Liu, A. Iotova, IEEE Trans. Ind. Electron. 56, 1548 (2009)

11. B.V. Chikate, and Y. Sadawarte, Int. J. Comp. Appl. Sci. Technol. 975 (2015)

12. D. M. Tobnaghi, R. Madatov, Intl. J. Adv. Res. Elect. Electron. Instr. Eng. 6404 (2013)

13. C. J. Rydh, J. Pow. Sourc. 80, 21 (1999)

14. M. Skyllas-Kazacos, M. H. Chakrabarti, S. A. Hajimolana, F. S. Mjalli, M. Saleem, J Electrochem. Soc. 158, 55 (2011)

15. N. Achaiboua, M. Haddadib, A. Maleka, Energy Procedia. 18, 538 (2012)

16. S. Anuphappharadorn, S. Sukchai, C. Sirisamphanwong, N. Ketjoy, Energy Procedia. 56, 352 (2014)

17. M. A. Green, K. Emery, Y. Hishikawa, W. Warta, E. D. Dunlop, Prog. Photovol. Res. Appl. 23, 805 (2015)

18. V. Singla, V. K. Garg, N. K. Malik, Int. J. Adv. Eng. Res. Sci. 2, 100 (2013)

19. M.Z. Hussin, M.H.A. Hamid, Z.M. Zain, R.A. Rahman, Contr. Sys. Grad. Res. Colloq. 55 (2010)

20. A. Beattie, "How to Calculate Return on Investment (ROI)," Investopedia, Aug. 31, 2020. Accessed on Oct. 11, 2020. [Online]. Available: https://www.investopedia.com/articles/basics/10/guide-to-calculating-roi.asp 